\title{
Information modeling of production and logistics processes in constructing using risk prediction tools
}

\author{
Tatiana Makartsova, Natalia Osadchaya, and Konstantin Tsapko* \\ Don State Technical University, 344002, Rostov-on-Don, Russia
}

\begin{abstract}
The purpose of the study is to develop a methodological approach to managing the main business processes of a large construction organization in a single information space, taking into account risk factors throughout the logistics chain, a comprehensive analysis of large construction organizations, including various enterprises involved in the production of finished products, from the production of reinforced concrete products to the commissioning of the object, was carried out, problems were identified that hinder their effective functioning. The object of the study is the business processes implemented within the logistics chain in large construction organizations. The subject of the study is a set of methods and models that can improve the efficiency of interaction between construction participants by synchronizing business processes and monitoring the entire logistics chain.
\end{abstract}

\section{Introduction}

At its core, technology platforms are non-trivial form of synergy and resources of different organizations. They are developed and operate in order to work out and implement programs for the development of advanced scientific, technical, technological achievements, the elaboration of promising areas of the technological process, and ensure their practical application. In this sense, technological platforms resemble the reproduction of the idea of scientific and production associations, which were created in the Soviet economy to implement a single cycle "science-technology-production-application", expanded to the scale of an industry and an intersectoral organization. In the current conditions, there is a shift towards the formation of state corporations, public-private partnerships, focused on the implementation of scientific and technical programs of a national character [1].

\section{Materials and methods}

An analysis of the activities of nine building organizations engaged in frame-monolithic and prefabricated-block construction, which are characterized by a variety of relationships

*Corresponding author: tsapko@list.ru 
between participating organizations, suggesting a complex coordination of the activities of the participants in the technological process shows the following:

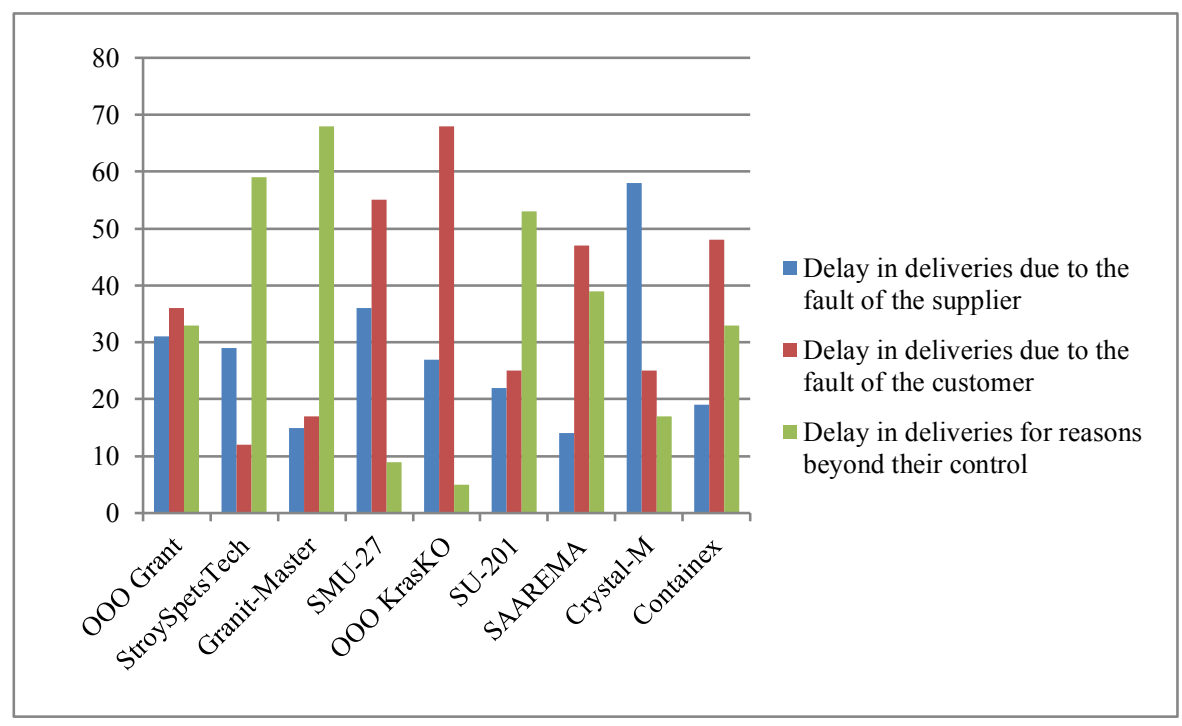

Fig. 1. Diagram of delays in the building of facilities

Of these, delays on the part of the customer for reasons:

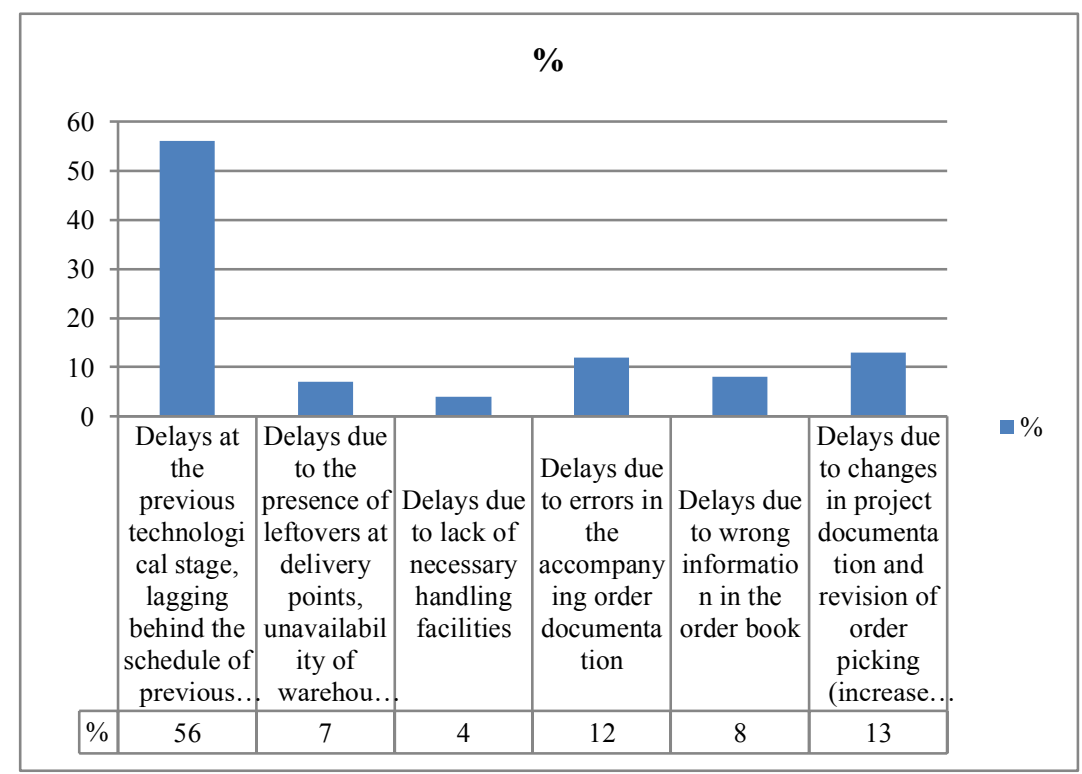

Fig. 2. Diagram of the reasons for the delay in delivery due to the fault of the customer

Of these, delays on the part of the supplier for reasons: 


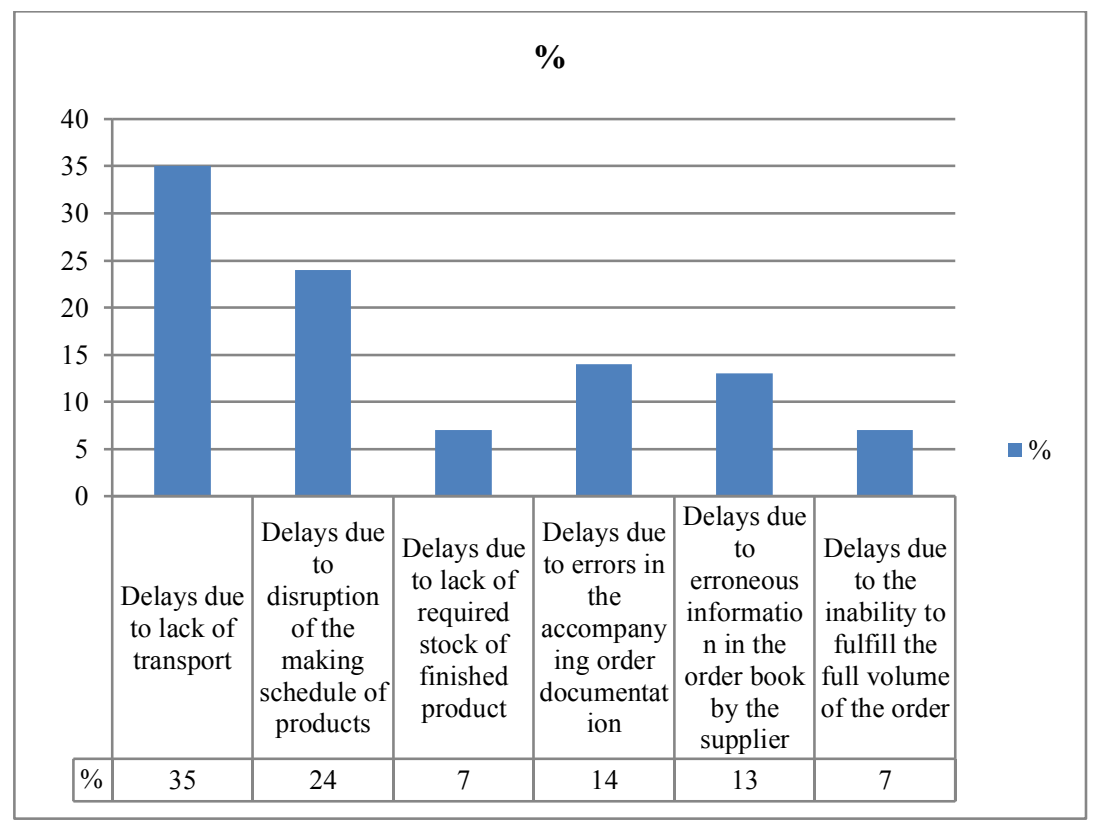

Fig. 3. Diagram of reasons for the delay in delivery due to the fault of the supplier

As the analysis data show, the main problem in the implementation of logistics and production tasks remains the inconsistency of the actions of the participants in the process the main percentage of delays is associated precisely with the backlog of technological procedures and the lack of timely adjustments to the delivery schedule [1-3].

Management of investment and construction activities at all stages of construction is considered as a process-based activity - a structured network of processes that "consume" resources and make products.

The process approach is considered as a set of actors. The activity of an actor as a set of interconnections existing between the participants in the building becomes transparent if the principles of three unities are observed the unity of design, production and technological, transport processes. For this study, the processes that form the production and logistics unity are of greatest interest [4-7].

As a methodological approach, the principle of the actor is used, that is, the acting subject of the construction cycle, which exists and is aimed at ensuring the entire investment and construction complex, retains its stability only in the unity of the feasibility of economic, organizational and technological components.

Forms of cooperation within the production and logistics chain of the analyzed companies show a high degree of entropy of the management system, which impedes the opportunity and economic feasibility of business processes. The reasons for this negative phenomenon are not only the conservatism of management decisions, but also the deliberate aggravation of the factors of instability by quasi-organizational decisions bureaucracy of management processes, errors in the organizational structure of management, lack of transparency in documented procedures for interaction between departments. The lack of common strategic goals among the participants in cooperation leads to the collapse of the investment cycle actor, in which he can no longer provide the functionality of the processes of the actors associated with it. This leads to problems and is a consequence of the uncertainty and conservatism of existing business processes. This 
trend is expressed in the absence of common strategic goals and interest in achieving them [12-15].

\section{Results}

The complexity of the relationship between companies that are part of a large building organization requires a clear organization and coordination of the work of all participants in the constructing organization, which performs work at all stages of construction, as well as the use of tools for managing possible risks. Special attention in the interaction of the participants of such a building organization deserves the complex logistic ties existing between them, which have developed within the framework of the implementation of the functions of planning, management and control of material, information and financial resources [8-12].

An important value of the logistic approach lies in the possibility of a formalized description of resource flows between building participants, modeling a system of integrated supply chains and taking into account additional conditions that affect the activities of construction organizations.

The result of the collapse of the actor is the disruption of the plans and deadlines for the implementation of the entire project, the rise in cost or the impossibility of completing constructing work, the loss of investors and customers.

Stabilization of the functional cycle of production and logistics processes is possible with an integrated management and predictive system of risk factors, which, when companies interact within the logistics chain, takes into account and allows the use of modern information modeling and lean building technologies.

The use of lean construction methods involves the implementation of LEAN-technology algorithms, in which the transfer from contractor to contractor is carried out as part of the completion of an entire technological stage, for example, from the preparation of the building frame to the installation of enclosing structures. The transition takes place without stopping production using integrated systems for assessing terms, volumes, resources and balances according to the reporting system entered into the database of all participants in the process, reporting on which is also recorded in the database and processed in the automated control system [13-15].

The most important condition for the efficiency of production processes in the company is compliance with planning and management, in particular the implementation of measures provided for by network planning. A common mistake is that the network schedules ignore the design work and only take into account the construction work that is being carried out. Even if the project works are mainly timed to the beginning of the journey and at first glance are not limited to deadlines, not including them in the schedule can also lead to serious consequences. A real assessment and determination of the necessary time for design and planning, strict coordination of work on various sections of the project, as well as timely accounting and involvement of the necessary forces of designers are hardly possible without careful planning of deadlines.

A prerequisite for a real assessment of the work in terms of time and necessary resources is the ability to present them in a visual form on a graph. The coding of the processes should provide a real assessment of each individual work according to these two criteria.

Proper coding of the work is also necessary to accurately determine the total time spent. Deviations of individual estimates to the greater or lesser side are well compensated along the path, if a sufficient number of such individual estimates are made on it. 
Since the network schedule serves as an auxiliary tool for monitoring and adjusting deadlines, the work should be divided according to the place of their execution, time and performers.

In network graphs, which are used to monitor the timing of work that is associated with a large amount of time, you should separate the intermediate results (events). Experience shows that when designing, it is advisable to carry out step-by-step control and coordination of the release of project documentation. However, when performing construction work, it is also recommended to include a clearly defined event in each route at least 10 working days later.

The main requirement is that the network schedule consistently includes only those processes that have a clear technically and logically determined relationship between them. All other processes should be presented as parallel work. It is not uncommon to make the mistake of creating logically and technically unsound relationships in structural analysis to address perceived resource bottlenecks. As a result, the network schedule readings are distorted, which, especially when optimizing deadlines and finding ways to reduce them, can lead to incorrect conclusions. The presence of unaccounted dependencies can also lead to similar consequences.

It often happens that there is only a conditional relationship between the large or complex works that follow one after another. A more thorough study shows that the end of the previous work and the beginning of the subsequent work can be combined in time. These features allow you to optimize most effectively, i.e. reduce the construction time. In network schedules of construction and installation works, one eight-hour working day is taken as a unit of time analysis. Network planning should not exhaust the possibilities of overtime work, as well as work on Saturdays and Sundays. They should be kept as a reserve of time in case of possible delays in the established deadlines.

It is important that the time estimates take into account the actual duration of auxiliary, preparatory and additional work. The calculation of the average values for the minimum, maximum and real time costs is rarely practiced when planning the production of work. Planners of construction and installation work usually have at their disposal reasonable experimental data to estimate the actual time spent. Experienced data on the minimum and maximum time spent in most cases is less clear.

\section{Discussion}

To automate the calculation of planned indicators, a control kit is used applying a constant array of control and measuring indicators developed at the design stage, compliance with which is an indicator of product quality. The comparison is made with the participation of the operator, but with a high degree of automation. Control parameters are compared according to the range of indicators and the operator is provided with information on compliance for making an expert-organizational decision.

Consequently, the creation of a forecasting and management system for the actors of the investment and building complex, taking into account the logistics and production processes in a single information space of the regional construction market, will effectively solve the main tasks of managing and coordinating work within large constructing organizations. Thanks to this, the resources of all its participants will be used as efficiently as possible.

The transport organization is the link between the production complex of material support and building and installation contractors. Each of these enterprises, within the framework of the investment and building process, acts as a subject that ensures the functioning of the subsequent organization, that is, an actor in the production and logistics process. Consequently, the information model is built taking into account three parameters: 
resource availability, resource intensity and time, the connecting factor between which is the production technology.

So, for the company "Crystal-D" specializing in monolithic-frame casting, the main technology is a set of installation and concrete works that determine the order and time of technological operations and the construction volume of a particular object is the volume and timing of resource consumption. This, in turn, determines the minimum and maximum boundaries of the terms and volumes of deliveries, the limits of risk intervals and uncertainties when predicting the production and logistics complex of processes. This determines the stability of the functioning of the actors: the production of concrete, metal products - transportation // intermediate storage (if necessary) - the production of construction and installation works - the acceptance of the stage and the transition to the beginning of the cycle.

The company "Containex", specializing in prefabricated house block building, connects the main production cycle with installation work on finished sections of buildings. Accordingly, the decisive factors are production of sections by contractors - selection of a transportation scheme and delivery to the object - placement of a section - setting and installation - acceptance and return to the cycle. At the same time, the stages of manufacturing and transportation of the section have an additional connection at the design stage, since the design of the section is directly related to the transport possibilities to the construction site.

Comparison of the algorithms for the functioning of actors indicates the difference in operational planning and the capabilities of forecasting and management using information technologies.

The traditional for Russia system of interaction management within the framework of production and logistics chain links in construction does not guarantee the stability of resource supply and the period of deliver. This destabilizes the rest of the factors in the investment and production complex. The complexity with a variety of accounting parameters, individualized for each company, determines the modularity of information software. The operational unit in this case is the production and technological module (PTM).

Production and technological module (PTM) - a set of delivery of products that ensures the execution of the design and technological stage, which is linked in the unity of the transport and production process.

Based on the complex of developed modules, it becomes possible to link the constructing technology and the sequence of work between all organizations involved in building: manufacturers of raw materials and semi-finished products, transport companies, contractors of construction and installation works.

\section{Conclusion}

The set of standard modules is tied to the nomenclature of objects (frame-monolithic buildings, precast-block, brick construction, etc.) and forms an information and reference base of a regional nature (IRB). The general contractor forms organizational and managerial decisions in project management using IRB data: data on the building site, constructing volumes, technology, construction period, transport infrastructure, resource suppliers, etc. The automated system for selecting modules allows you to find optimal planning solutions, taking into account the possibility of choosing a production and logistics chain with predicting a probabilistic scenario of actions.

The use of IRB when choosing organizational solutions in project management allows you to interconnect such basic processes as:

- $\quad$ loading of parts, materials for building at the locations of resource suppliers; 
- $\quad$ transportation of cargo data to building objects;

- production of building and assembly works.

The processes considered above are the basis for making an information model of production and logistics processes in building in a single information space.

Ensuring the timely commissioning of a building facility is achieved by linking the time of organizing the work of the main participants interacting in the framework of the construction: manufacturing concerns, transport organizations, companies performing construction and installation work.

\section{References}

1. J. Čamaj, J. Mašek, M. Kendra, Procedia Engineering 134, 224-230 (2016). doi: 10.1016/j.proeng.2016.01.063

2. M. Hlatka, R. Kampf, G. Fedorko, Jour.-Techn. Educ. Manag. Inform. 9 (3), 889-898 (2020). doi: 10.18421/TEM93.

3. M. Zoldy, Int. J. Automot. Technol. 20, 971-978 (2019). doi:10.1007/s12239-0190091-y.

4. A. Beskopylny, A. Chukarin, B. Meskhi, A. Isaev, Transportation Research Procedia. IX International Scientific Siberian Transport Forum - TransSiberia 2020. 39-46 (2021). DOI:10.1016/j.trpro.2021.02.045

5. A. Beskopylny, B. Meskhi, A. Veremeenko, A. Isaev, E. Kadomtseva, Transportation research procedia. IX International Scientific Siberian Transport Forum - TransSiberia 2020. 84-91 (2021). doi:10.1016/j.trpro.2021.02.050

6. B.Ch. Meskhi, V.N. Azarov, A.I. Evtushenko, Ju.V. Startseva, IOP Conference Series: Materials Science and Engineering. 012058 (2020). doi:10.1088/1757899X/1001/1/012058

7. M. Poliak, Ener. sour. 7, 25-29 (2019). doi: 10.1080/15567036.2020.1776796

8. R. Rajkovic, N. Zrnic, S. Bojic, Transport. In: Commer. Transp., 159-173 (2016). doi:10.1007/978-3-319-21266-1_10.

9. G.V. Bubnova, O.V. Efimova, I.V. Karapetyants, P.V. Kurenkov, MATEC Web of Conferences. (ICOEME 2019). 02013 (2018). doi: 10.1051/matecconf/201823602013

10. J.V. Gnezdova, V.I. Deren, E.N. Rudakova, I.V. Karapetyants, A.A. Safronova, Intern. Jour. Engin. Techn (UAE) 4, 201-204 (2018). doi: 10.14419/ijet.v7i4.38.24442

11. O.D. Pokrovskaya, International Scientific Conference (GCPMED 2018) 10, 91-101 (2018). doi: https://dx.doi.org/10.15405/epsbs.2019.03.10.

12. T.B. Mikheeva, E.V. Murugova, SHS Web of Conf (2019). doi.org/10.1051/shsconf/20197007003

13. S.V. Pervukhina, O.A. Evtouchenko, L.Iu. Kotliarenko, M.P. Churikov, SHS Web of Conferences. Curr. Iss. Mod. Ling. Hum. 232-244 (2020). doi: 10.1051/shsconf/20208801013

14. A. Kusters, M. Spotti, R. Swanwick, E. Tapio, Int. J. Multiling. 14 (3), 219-232 (2017). doi:10.1080/14790718.2017.1321651 